\author{
Valentina Rey Domínguez \\ Universidad de Chile \\ valentinareyd @gmail.com
}

\title{
No hay perros guardianes, solo un mito sobre el poder
}

\author{
There are no guard dogs, only a myth about power
}

\begin{abstract}
Resumen
Durante décadas el mito periodístico ha servido para explicar la profesión, dotarla de sentido, identidad y legitimidad; otorgándole así un rol dentro de la sociedad. Bajo el ideal de "cuarto poder del Estado", "perro guardián de la democracia", el mito ha instalado valores éticos que han normado las prácticas y actitudes profesionales. Sin embargo, la realidad da cuenta de una distancia entre aquel ideal y el ejercicio periodístico; una dicotomía entre el mito y la práctica. El presente ensayo propone que aquel problema radica en el mito, en una construcción enunciativa que teóricamente presenta una imposibilidad práctica, pero que establece una relación de poder que limita y norma las actitudes periodísticas, instalando principios éticos como verdades absolutas y doctrinarias. Por lo tanto, nos proponemos cuestionar los mecanismos de producción de verdad presentes en el mito; aquellos que fijan un orden de relaciones, en cómo el periodista debe entender y ejecutar su profesión.
\end{abstract}

Palabras clave: Mito, Producción de verdad, Identidad

\begin{abstract}
For decades the journalistic's myth have been used to explain the profession, to give it meaning, identity and legitimacy, granting it a role in society. Under the ideal of "fourth state power", "watchdog of democracy", the myth has installed ethical values that have ruled the professional practices and attitudes. However, reality shows a distance between that ideal and the journalistic exercise; a dichotomy between myth and practice. The present essay proposes that this problem lies in the myth, in an enunciative construction that theoretically presents a practical impossibility, but that establishes a relation of power that limits and normative journalistic attitudes, installing ethical principles as absolute and doctrinal truths. Therefore, we propose to question the mechanisms production of truth present in the myth; those that establish an order of relations in how the journalist must understand and execute the profession.
\end{abstract}

Keywords: Myth, True production, Identity. 


\section{Valentina Rey Domínguez}

\section{El rol del periodismo en la historia}

La historia del periodismo va de la mano de una serie de procesos sociales, políticos y económicos que han determinado el ejercicio, pero sobre todo, la identidad profesional. Sin embargo, más allá de las teorías que buscan dilucidar el funcionamiento de los medios de comunicación y el rol de la profesión en la sociedad, el recorrido por esta historia nos permite entender en qué momento, o momentos, el periodismo dejó de ser un canal de información y se convirtió en el "cuarto poder del Estado" o en el "perro guardián de la democracia." En ese sentido, es interesante considerar que la comunicación social -como se ha llamado al proceso de transmisión de información durante muchas décadas- ha existido a lo largo de toda la historia y en todo tipo de sociedad, pero hay un momento de quiebre donde se evidencia una evolución y profesionalización de aquella labor, pasando de un oficio no especializado a una profesión que forma parte de un sector económico con delimitación de funciones, conductas, responsabilidades y objetivos; las que han sido justificadas a partir de la construcción de un discurso que le otorga valor a la profesión.

Entendemos por lo tanto que la profesionalización del periodismo marca los límites y establece un discurso que separa la profesión de la comunicación ordinaria. Este discurso es lo que conocemos como mito profesional, el cual además de dotar de sentido la profesión establece una identidad fuertemente marcada por el valor que adquiere la profesión a través de este relato mítico. Ahora bien, en la historia de esta profesión se ha hecho evidente la existencia de una dicotomía entre la práctica y el mito. Lo que aquí se propone, es que estos "perros guardianes de la democracia" no serían más que guardianes de una ilusión que esconde la consolidación de un juego de relaciones de poder. Se trata entonces de un dominio y poder sobre los cuerpos, que no se limita solo a los periodistas mediante un -supuesto- control de las actitudes profesionales, sino también involucra a todos los sujetos que componen la sociedad. Puesto que el mito se instala dentro del imaginario colectivo a través de una verdad profesional y doctrinaria; lo que explicaría la vigencia del relato a pesar de su evidente imposibilidad. Por ende, la dicotomía radicaría en la producción de verdad presente en el mito, la cual busca hacer sentido y de esa forma, lograr efectos de poder tanto al interior como fuera de la profesión. 


\section{Valentina Rey Domínguez}

Si bien aquella hipótesis cuestiona directamente la verdad del mito y por ende propone una búsqueda y análisis de aquellos mecanismos de producción de verdad en el relato profesional, no se aleja de la dimensión práctica puesto que a lo largo de toda la historia la comunicación social y posteriormente el periodismo, ha estado en constante relación con el poder:

"La comunicación social ha existido desde siempre porque se trata de aquellas fórmulas en que las sociedades se las arreglan para codificar primero y transmitir después principios básicos de supervivencia e identificación. Y para, en una segunda fase, justificar primero y mantener después la organización del poder." (Barrera, 2004: 25)

Durante la época de los grandes imperios en la Edad Media e incluso anterior a ella, la comunicación social siempre ha oscilado en espacios de poder. Los primeros gobernantes, emperadores y monarcas, pagaban a personas de su confianza para que recopilaran información que les pudiera ser útil, pero también que sirviera para ser difundida en la sociedad a modo de marketing político. Sin embargo, el periodista como tal, se constituye en el Renacimiento con las hojas a mano, los avisos y las gacetas informativas difundidas en el espacio público; espacio que permitía que las ideas de la ilustración recorrieran distintos sectores a través de la comunicación social. Durante la I y II Guerra Mundial el periodismo fue un arma elemental de las grandes potencias a la hora de difundir propaganda política, pero sobre todo la verdad de la guerra, lo que parecía ser una fuente de información para las personas, generando una especie de comprensión y explicación de lo que ocurría en el mundo y del por qué sus condiciones de vida se veían alteradas. Cada sociedad tenía su verdad, que era producida por quienes estaban en el espacio físico e intelectual de la guerra, pero al mismo tiempo compartían principios frente al ejercicio periodístico que hacían referencia a un plano práctico al instalar, por ejemplo, como metodología de trabajo la "pirámide invertida" mientras que en el plano abstracto o de las ideas, la ética ya aparecía como un principio de la profesión al ser un factor que legitimaba la labor periodística. Sin embargo, no es hasta el establecimiento de las ideas liberales de -orden político y 


\section{Valentina Rey Domínguez}

económico- que el periodismo se profesionaliza y se instala como el "cuarto poder del Estado", "defensor de la democracia."

No es casualidad que esto ocurriera en medio de un cambio en el modelo económico a nivel mundial y posterior a las dos guerras más violentas del mundo. Los enunciados anteriores que definen el rol de la profesión dejan claro una responsabilidad social por la protección de la democracia, esto porque después de las guerras y los regímenes totalitarios, la democracia era un bien preciado que aseguraba un bienestar generalizado para las sociedades y al mismo tiempo, este sistema político permitía que el nuevo modelo económico tuviera sentido, pues apelaba y aseguraba el respeto a las libertades individuales y de expresión, abriendo paso a un sistema económico privado donde la intervención del Estado era limitada. Es en este contexto que se dota de sentido político - por la capacidad de incidencia- y ético - por la responsabilidad social- al periodismo, estableciendo un relato mítico que por años le ha dado identidad y legitimidad a la profesión. La evolución del periodismo no solo es en cuanto al rol que ocupa en la sociedad, que por lo demás siempre ha sido relevante al momento de ser un factor articulador, sino también da cuenta del paso de un oficio a un sector económico, pues al profesionalizarse se constituye como un sector que genera ganancias y que, sobre todo, logra capitalizar poder político y social.

\section{El mito profesional: el Quijote del periodismo.}

La evolución en torno al sentido y rol del periodismo en la sociedad permitió instalar un mito profesional con valores y características estables en el tiempo, porque este ofrece - hasta el día de hoy-, una explicación universal de la profesión. El periodista pasó a ser el medio por el cual la sociedad se liberaría del poder que ejercía el Estado sobre las personas. Su profesionalización sirvió para institucionalizar aquel relato mítico y normar las conductas de los

profesionales a través de códigos deontológicos, leyes de prensa, manuales profesionales, etc., pero sobre todo, para instalar el discurso al interior de las escuelas de periodismo; lugar donde el mito se ha establecido como una verdad absoluta y moralizante. Esto último, porque aquel relato se sustenta a partir de valores éticos que norman las conductas profesionales, pero sobre todo, dan cuenta de características personales que deben tener quienes quieran cumplir con aquel rol. En esa línea, Javier Darío Restrepo planteaba que la ética no era algo ocasional o esperable de la 


\section{Valentina Rey Domínguez}

profesión, sino más bien un valor que debe acompañar al periodista como el zumbido al moscardón (Restrepo, 2004: 11). Por tanto, la dimensión ética jamás se debe separar de la práctica profesional y personal.

Este deber ético se sustenta a partir del análisis de una sociedad compleja, que se vio fuertemente golpeada por las dos guerras mundiales, por lo que en la construcción de una sociedad democrática, sin violencia y sobre todo libre, el periodismo permite garantizar el rol de una sociedad y profesión fiscalizadora ante los poderes políticos, asegurando de esa forma que las necesidades de las personas sean prioridad para los gobiernos y que los Derechos Humanos se respeten; considerando el derecho a la información y a la expresión. Por lo tanto, la responsabilidad social del periodismo exige constantemente un comportamiento adecuado por parte de los profesionales, bajo los estándares éticos que demanda el deber de "proteger la democracia". Pero para lograr eso, los periodistas deben tener la convicción y estar completamente seguros de que su labor es capaz de derribar gobiernos antidemocráticos y corruptos:

"Se necesita en esta profesión una dosis de idealismo tan grande como la del Quijote para mantenerse en la convicción de que las palabras impresas o habladas de un periodista pueden cambiar ese panorama de injusticia." (Restrepo, 2004: 20)

Por lo tanto, el mito tiene dos dimensiones, una social y otra personal. Por un lado, el mito explica ante la sociedad en qué consiste la profesión, cuál sería su rol e importancia para el fortalecimiento de la democracia. Mientras que por otro, encarna la ambición personal, los sentimientos de grandeza que distinguen al periodista del resto de las personas y profesionales. Cuántas veces se habrá visto a un profesor en clases de ética periodística inflar su pecho y hablar horas de cómo destapó un caso de corrupción o las malas prácticas políticas de tal representante, como si su valoración personal dependiera de ello. "Somos comunicadores, podemos hacerlo" se repite una y otra vez en asambleas o reuniones de estudiantes de periodismo, cada vez que se discute la coyuntura nacional; todos los años más de cien Quijotes de la Mancha se sumergen en la ilusión de ser los héroes de la sociedad con su arma principal; el mito profesional. Pero, 


\section{Valentina Rey Domínguez}

independiente de si el periodista podrá o no terminar con el hambre en el mundo, el terrorismo y las malas prácticas políticas ¿por qué es él quien debe ocuparse de eso? El mito se ha encargado de mantener la ilusión de poder y status social que se puede alcanzar mediante el correcto ejercicio profesional.

Kapuscinski (2006) diría que lo que distingue al periodista del resto de las personas y que por tanto, les permitiría arrojar la primera piedra, es que el periodismo es una profesión que forma parte del estilo de vida de los profesionales y no todos tienen la valentía de asumir semejante reto, el único modo de realizar un trabajo perfecto es llevar los valores éticos de la profesión a todos los ámbitos de la vida personal. El mito opera como una construcción narrativa que además de dotar de sentido a la profesión e idealizarla ante los ojos de los periodistas, estructura un espacio simbólico. Establece valores y normas conductuales que no sólo le dan poder a la profesión, sino también al sujeto profesional, puesto que lo envuelve con la ilusión de superioridad ante resto de las personas, creando una diferencia ética con los sujetos que forman parte de aquella "masa" ignorante a la cual el periodismo contribuye en su educación; lo que responde a la idea de una educación jerárquica, donde hay quienes conocen y manejan la información y la "difunden" hacia las masas, estableciendo quienes están arriba y quienes abajo. Muy propio de sistemas de poder y dominación permeados por las ideas de la Ilustración.

Lo paradójico de esto, es que la educación de las masas, gracias al acceso a la información, permite la organización y articulación de la sociedad en pos de que esta pueda fiscalizar el poder y cuidar de la democracia sin la necesidad de un perro guardián. Pero ¿no era eso la prensa obrera? un medio por el cual la gente se organizaba mediante demandas y convicciones comunes. Entonces ¿por qué existe un debate en torno a si puede ser o no considerada como periodismo? Su cuestionamiento, que nace luego de las teorías periodísticas donde el mito ya estaba instalado, siempre se ha enfocado en la falta de objetividad a la hora de comunicar ¿casualidad? Esto, si además consideramos que la prensa obrera surge durante la ilustración y decae cuando las ideas liberales se consolidan en la sociedad, señala una relación directa entre este último momento y la consagración del mito, acompañado de la profesionalización del periodismo. ¿Cómo puede el periodismo organizar la sociedad siendo objetivo, cuando la organización siempre va acompañada de una ideología hegemónica? Por lo 
tanto, podemos dar cuenta de que el mito, al establecer un rol profesional con valores estables, lo que hace es delimitar los espacios de participación, instalando relaciones de poder donde el periodista se presenta como el gran actor social sobre la masa.

Es en ese contexto en que la objetividad asoma como el gran valor intransable de la profesión, a tal punto que se ha instalado la idea de que no podríamos pensar en un periodismo que no sea objetivo. Esto es interesante, puesto que bajo esta premisa el periodismo se limita a ser meramente un canal de información. Pero el mito plantea que el periodista transmite información y al mismo tiempo es el encargado de actuar por la sociedad: ¿cómo debería entenderse ese actuar objetivamente?

Los cuestionamientos ante la objetividad del periodismo son muchos y van en distintas direcciones, desde planteamientos que consideran que el solo hecho de jerarquizar la información constituye una práctica poco objetiva; u otros que subrayan la imposibilidad de desprenderse de la opinión personal al momento de narrar un acontecimiento, etc. Sin embargo, todas aquellos debates o críticas demuestran que el mito establece una verdad profesional que no coincide con la realidad, es decir que presenta una dicotomía entre el deber ser y la práctica. De todas formas, este valor sigue siendo considerado como un elemento fundamental en el quehacer profesional, donde este ejercicio práctico es lo que - entre otros valores- legítima ante los ojos de las personas la práctica profesional. En efecto, el periodismo no podría considerarse como cuarto poder del Estado y fiscalizador de los poderes políticos si no fuera objetivo. Sin embargo, los códigos deontológicos y manuales profesionales han ido modificando el concepto de objetividad por el de "veracidad" o "verdad", apelando a la transparencia de la profesión y evitando así el cuestionamiento inevitable a la existencia de la objetividad: "el respeto a la verdad y al derecho del público a la información veraz es el primer deber de todo periodista." (Código deontológico, UNESCO 1986) En esa línea, Javier Darío Restrepo, como buen profesional encandilado por el mito, planteaba que el buen periodista construye su ética profesional sobre la base de la verdad, puesto que aquello significa responsabilidad, y sobre todo, servicio (Restrepo, 2004:46), entendiendo la verdad como un elemento que le pertenece a la sociedad y no al periodista.

A partir de la revisión de códigos deontológicos, manuales profesionales y leyes de prensa de cinco países, aparecieron cuatro valores que se repetían constantemente como elementos fundamentales de la profesión: veracidad, responsabilidad social, independencia y libertad de 


\section{Valentina Rey Domínguez}

expresión. Cuatro valores que mantienen una relación complementaria y directa entre ellos, puesto que el periodismo define su rol a partir de la responsabilidad social que se le adjudica. Ahora bien, para llevarla a cabo, es necesario asegurar un trabajo veraz en cuanto a la información que se entrega; independiente de los poderes políticos y económicos, asegurando así que aquella información no será intervenida por los intereses de pequeños grupos de poder. Cumpliendo de ese modo, uno de los derechos humanos básicos: la libertad de información y expresión de todos los ciudadanos. Si bien durante los últimos años el periodismo ha sido cuestionado justamente por no responder a aquellos valores, estos siguen siendo la base del mito profesional, por lo que a pesar de los cuestionamientos no hay un cambio en torno al rol que cumple el periodismo en la sociedad, muy por el contrario, se le exige aún más en contextos donde su ejercicio se ve debilitado. Lo que responde a una definición doctrinaria y universal en cuanto a la identidad profesional.

\section{Los perros guardianes del poder}

Es en este escenario donde vemos el mito como un espacio donde se establecen distintas relaciones de poder. Es decir, cuando se propone que la dicotomía entre el ejercicio periodístico y el mito radica justamente en el mito, lo que se está diciendo es que hay una producción enunciativa que además de establecer una verdad, fija relaciones de poder al interior de la sociedad. Esto, porque el mito dispone de los cuerpos en torno al poder de un relato simbólico desde el momento en que establece una relación asimétrica entre los periodistas y el resto de la sociedad; por lo tanto, estos, conscientes o no, son los perros guardianes del poder que les otorga su profesión, pero sobre todo, del poder que les entrega el mito.

Podríamos entonces considerar el mito como uno de aquellos mecanismos que tiene la sociedad o los pequeños grupos poderosos para ejercer y crear relaciones de poder asimétricas mediante el disciplinamiento de los cuerpos y el control de la vida social de los sujetos. Esto se evidencia en los códigos deontológicos, manuales profesionales y leyes de prensa, los que al normar las conductas profesionales mediante valores y un ideal de deber ser, materializan el mito disciplinando a los sujetos profesionales y sumergiéndolos en un espacio de control subjetivo a través de la internalización de una verdad que encarna un poder simbólico; pues la ilusión mítica 


\section{Valentina Rey Domínguez}

es sobre el poder que tiene el periodista sobre la democracia, la sociedad e incluso el Estado. Es una relación recíproca, puesto que el poder que puede tener un periodista crece en la medida que el mito se fortalece y se mantiene presente tanto en la sociedad como en la profesión, de modo que el relato necesita del periodista así como el periodista al mito.

Por otro lado, bajo esta lógica no sólo podríamos considerar que el periodista es sujeto de dominación y disciplinamiento, sino todos los individuos que componen la sociedad; no sólo por la relación asimétrica que se establece entre el periodista y la 'masa', sino más bien porque el mito se legitima gracias a la sociedad. Sin embargo, independiente de aquello, lo interesante es que el mito, al establecer distintos tipos de relaciones de poder, lo que hace es convertir la profesión periodística en un elemento útil para las sociedades modernas y sobre todo para el poder. De ahí la necesidad de normar y moldear conductas, lo que asegura aquel efecto.

"La normalización, llega a crear una especie de jerarquía de individuos capaces o menos capaces, el que obedece a una norma determinada, el que se desvía, aquel a quien se puede corregir, aquel a quien no se puede corregir, el que puede corregirse con tal o cual medio, aquel en quien hay que utilizar tal otro. Todo esto, esta especie de toma en consideración de los individuos en función de su normalidad, es creo, uno de los grandes instrumentos de poder en la sociedad contemporánea" (Foucault, 2012: 36)

Si bien la forma más visible del ejercicio del poder -el cual entendemos como la capacidad de imponer la propia voluntad sobre la voluntad ajena-, es mediante la utilización de la fuerza, en las sociedades modernas la racionalidad es un elemento por donde se ejerce poder, pues se controla la subjetividad y capacidad de razonar de las personas. Es por esto que el mito, al ser una construcción que manifiesta una voluntad de saber y poder, constituido a partir de elementos que forman parte del universo abstracto y simbólico, que se relacionan con la realidad material pero que no significa una relación equivalente entre el discurso -relato- y la práctica concreta; logra su efecto de poder y control de los cuerpos. 


\section{Valentina Rey Domínguez}

Ahora bien, lo interesante es que podríamos considerar que el mito establece distintas relaciones de poder, la primera entre el periodista y su profesión de forma consensuada. Puesto que el mito necesita de la convicción de los periodistas para ejercer su poder y el periodista necesita del mito para legitimar su poder. Se trata entonces de una relación diferente a la que se establece entre la sociedad y el mito o la sociedad y el periodista. Ya que si bien se puede decir que la sociedad tiene poder sobre el mito -al ser ella quien lo legitima y permite su ejercicio-, el mito a través de sus mecanismos ha logrado disputar el sentido de las personas, quienes han adoptado como una verdad casi absoluta aquel relato que le da poder a la profesión, que la dota de identidad y sentido en los sistemas políticos democráticos. De esta manera sí podríamos establecer una imposición del relato.

Sin embargo, los periodistas se ven encerrados en aquella relación de poder "consensuada", al igual que el Quijote en su ilusión. Esto porque el mito establece un relato donde el rol de la profesión, además de velar por el correcto ejercicio de la democracia, asegura el derecho a la libertad de expresión e información que tienen las personas. Pero al plantear la objetividad como valor fundamental de la profesión, el mito excluye a los periodistas del ejercicio de su libertad de expresión, de forma personal y profesional, ya que, según el mito, el periodista es periodista las 24 horas del día.

Ahora bien, las relaciones de poder planteadas, se establecen a partir de la "verdad" sobre la profesión que busca instalar aquel relato. Cumpliendo una función de adoctrinamiento casi invisible, el relato que dota de sentido al periodismo se ha transmitido casi sin cuestionamientos por años en las escuelas de periodismo, medios de comunicación, institutos profesionales, etc; quedando por escrito en manuales profesionales, códigos de ética y leyes de prensa. Pero como todo sueño, este se termina en algún momento. Es ahí donde el periodista, que ya se dio cuenta que la realidad se distancia de aquel relato mítico, acepta acercarse a aquel sueño u olvidarlo y sumergirse en la rutina; pero siempre cuidando el mito, pues este disculpa la pasividad e imposibilidad de llevar a cabo titánica misión. 


\section{Valentina Rey Domínguez}

\section{La moral, mecanismo de legitimidad}

El mito propone una supuesta verdad sobre el periodismo que es validada por los profesionales y la sociedad en su conjunto, lo que ha permitido que hasta el día de hoy funcione como la explicación oficial de la profesión. Ahora bien, esta verdad se construye e instala a partir de mecanismos de producción de verdad que, en primera instancia, trabajan a partir de la premisa de que la verdad política y el conocimiento no forman parte de la naturaleza humana, sino más bien son un invento de las personas que buscan sacar rédito de aquella construcción. El poder, la obtención y ejercicio de este, no sólo reprime sino que también produce saber, sentido y efectos de verdad (Foucault, 1973).

Por lo tanto el poder que ejerce el mito sería sobre la subjetividad y racionalidad de las personas, al hacer pasar una idea falsa por verdad "absoluta". Es por esto que podríamos identificar que los mecanismos que operan en aquella producción de verdad serían mecanismos de instalación, demostración y legitimación. Ya que, en un primer momento, se instala en la subjetividad de las personas esta idea y explicación sobre la profesión, la que establece un rol, valores y conductas a seguir. Mientras que, casi en paralelo, se plantea un valor que viene a demostrar que es posible llevar a cabo esta labor: la objetividad o la veracidad. Este elemento carga con todo el componente moral de la profesión, puesto que en pocas palabras lo que dice es: el periodista dice la verdad. La objetividad funciona como la prueba o garantía de que lo que instala el mito es real, por lo que basta con catalogar el trabajo periodístico como veraz u objetivo para demostrar con "hechos" la bajada práctica del mito. La objetividad, por tanto, es un elemento discursivo y estratégico que ha servido por años para defender la profesión ante los cuestionamientos sociales (Tuchman, 1999).

Ahora bien, estamos ante un tipo de verdad que es aceptada gracias una producción de sentido basada principalmente en elementos morales y éticos. No es una verdad que responda a una demostración empírica, sino más bien a la ilusión que la rodea. En ese sentido, la moral, que en este caso traspasa el ámbito profesional y apela directamente a la calidad valórica de quienes ejercen el periodismo, logra legitimar un relato mítico que no establece una relación "discursopráctica concreta", sino más bien instala una relación directa entre "discurso-verdad simbólica", donde la ética y la moral logran darle credibilidad y sustento valórico al mito. 
Valentina Rey Domínguez

En paralelo a los mecanismos de instalación, demostración y legitimación, la verdad del mito se construye a partir de mecanismos discursivos. Es decir, este solo tiene sentido a través del lenguaje, pues es ahí donde aquellas especificidades adquieren la comprensión necesaria para lograr su efecto de poder.

"El mito es lenguaje, pero lenguaje que opera en un nivel muy elevado y cuyo sentido logra despegar si cabe usar una imagen aeronáutica, del fundamento lingüístico sobre el cual había comenzado a deslizarse." (Lévi-Strauss, 1995: 233)

A través de su construcción discursiva, el mito logra hacer encajar aquellos procesos y mecanismos que instalan y legitiman el relato al interior de la profesión y la sociedad. Ernesto Laclau, plantea que la retórica es el arte de hacer pasar lo malo por bueno y en este sentido el mito periodístico logra darle poder a una profesión que en la práctica no es el cuarto poder del Estado, pero que a pesar de no serlo, mantiene su poder, su legitimidad y, sobre todo, la ilusión de lo que debería ser: como un acto de autocomplacencia o romanticismo. Este fenómeno es lo que Laclau aborda como el misticismo de los relatos míticos, donde a partir de diversos mecanismos lingüísticos, hay una producción de sentido que logra alterar una realidad o verdad, a partir de la representación simbólica que se da gracias al lenguaje (Laclau, 2002). De este modo, el mito consigue un efecto de verdad y poder por su construcción discursiva y los mecanismos de instalación, demostración y legitimidad que forman parte de la producción de verdad.

En esta línea, es necesario mencionar que la verdad que establece el mito representa una falsa idea a nivel de conciencia, apelando a la subjetividad individual y colectiva, pues su legitimación es social. Marx (1974) planteaba que los pensamientos, ideas e ilusiones de la conciencia significan una atadura y limitación para los individuos, al hacer pasar falsas ideas por verdades "absolutas", alejando de esa forma la representación que un sujeto puede tener o hacer sobre el mundo de la realidad material. En ese sentido, el mito periodístico se debe considerar como una construcción idealista, que instala una falsa idea sobre la profesión además de provocar una autoalienación de la razón. Todos los años hay miles de estudiantes que entran a las escuelas de periodismo deseosos de ser los héroes de las comunicaciones. En el camino pueden mantener 


\section{Valentina Rey Domínguez}

o no aquella romántica ilusión, pero siempre es una opción. Es el periodista que por aquel romanticismo o ego profesional decide entrar al juego del mito y adoptarlo como verdad.

Estas "ilusiones" o "fantasías" de la profesión, se presentan de forma doctrinaria puesto que no permiten una concepción distinta del rol y quehacer profesional, estableciendo normas, valores y procedimientos conductuales como reglas obligatorias para el correcto desarrollo profesional. Por lo tanto, podemos entender los mecanismos de instalación, demostración y legitimación dentro de un proceso de adoctrinamiento, el cual mediante la enseñanza, por ejemplo en las escuelas de periodismo, establece y naturaliza aquel relato en la sociedad.

Por otro lado, el adoctrinamiento tiene lugar porque la verdad del mito se compone en gran parte por la ideología que lo rodea. Esta la entendemos como una dimensión de representación discursiva que logra distorsionar la realidad mediante la producción y los efectos de sentido. Lo que en palabras de Zizek podríamos categorizar dentro de la tríada lacaniana de lo real, lo simbólico y lo imaginario (Zizek, 2003). Por lo tanto, el aporte de la ideología dentro de esta relación va en la línea de simbolizar lo real a través de mecanismos de adoctrinamiento y sentido, alterando aquella realidad y estableciendo un correlato ético-político. Lo anterior en ningún caso logra ser un proceso objetivo, puesto que la ideología propone una visión de mundo que en este caso el mito adopta e instala como verdad absoluta de la profesión. Retomando los mecanismos de producción de verdad que tiene el mito, en el proceso de instalación, demostración y legitimación, la ideología logra transformar la realidad mediante lo simbólico, apelando a la racionalidad y subjetividad de las personas. Lo que podríamos definir en etapas de producción de verdad como: un primer momento de construcción discursiva donde la ideología actúa como medio que permite, a partir de sus características, alterar la realidad y dotarla de nuevas significaciones. Ahora bien, para que aquello pueda provocar su efecto de saber y poder es necesario que el mito logre instalarse y ser aceptado en la sociedad. Por lo mismo el segundo momento es el proceso donde aquella construcción discursiva logra hacer sentido y se establece instala- como una realidad y verdad posible. Sin embargo, al apelar al razonamiento de las personas es necesario “demostrar" que aquella propuesta de verdad es real y por lo mismo, la objetividad funciona como un valor que da cuenta de la realización práctica del mito. 


\section{Valentina Rey Domínguez}

todas formas, como se mencionaba anteriormente, en una última instancia el mito logra legitimarse a través de la moral, elemento que condiciona la profesión. El relato logra su universalidad mediante aquellos valores morales, los que apelan al sentido común de las personas en cualquier parte del mundo. Lo que explica también que el relato -además de sus características lingüísticas- mantenga una coherencia a nivel mundial y que, en diferentes países, el rol del periodista sea el mismo: cuidar la democracia y fiscalizar los poderes políticos y económicos. La moral actúa como un mecanismo de autorregulación de la conciencia. En ese sentido, no es casualidad que los códigos deontológicos normen las conductas profesionales con más poder que las leyes de prensa, ya que estos documentos son los que ratifican los deberes morales de los profesionales, por ende también la identidad del periodista.

"La ética proporciona un marco de trabajo para dirigir las funciones esenciales de los periodistas, establecer políticas y desarrollar estrategias para velar por el correcto ejercicio profesional.” (Colegio de periodistas, 2015: 1)

Los principios éticos y morales son elementos constitutivos de sentido, que logran legitimar el mito a pesar de su imposibilidad práctica, porque son valores abstractos que actúan como leyes y normas al interior de la profesión, pero también a nivel social. Puesto que la moral también funciona como una forma de interpretar y dotar de sentido y explicación, cosas y comportamientos que no necesariamente la tienen. Ahora bien, cuando se plantean e instalan formas de interpretar la vida, la historia, una profesión, etc., se establece una relación de poder, puesto que hay una lucha o enfrentamiento entre perspectivas donde una resulta hegemónica y por ende, logra instalarse y legitimarse socialmente. La lucha entre el bien y el mal es una lucha entre dos formas de entender y valorar las conductas. Por lo tanto, cuando se establece que tal conducta es buena o mala moralmente, hay una idea hegemónica que se instala y por lo tanto se logra aplicar y legitimar como axioma, al mismo tiempo que se premia, castiga o norma. 


\section{Valentina Rey Domínguez}

\section{Conclusiones}

Cuestionar el mito y los mecanismos de producción de verdad que operan al interior de aquel relato, nos permite comprender la profesión como un campo de constantes luchas de poder, que buscan poseer un control sobre las formas de interpretar el mundo, los procesos sociales y sobre todo, las relaciones y comportamientos sociales. Ahora bien, este es un análisis abierto, que deja distintas interrogantes en torno al poder que tiene el mito, el periodismo y los periodistas; y por otro lado, el poder que tiene la sociedad sobre aquel relato, en cuanto su aceptación y legitimación. Los múltiples mecanismos que operan en el mito funcionan como una red de sistemas interconectados, que trabajan a la par y al mismo tiempo, desde distintos lugares de intervención, pero todos operan a nivel de conciencia. Aquellos mecanismos de producción de verdad y efectos de poder han logrado transversalizar valores éticos y conductas esperables al interior de la profesión, universalizando un relato que le otorga sentido al quehacer periodístico, y al mismo tiempo, le adjudica un rol en la sociedad a partir de una supuesta verdad absoluta.

¿Para qué sirve el poder del mito? ¿Para manejar la opinión pública a partir de una ilusión o engaño respecto a la profesión? ¿Para controlar el espacio público y los sujetos que habitan en él? ¿O simplemente para darle sentido a una profesión y de paso, llenar de ilusiones de grandeza a aquel joven periodista que quisiera ser el perro guardián de la democracia?

Foucault planteaba que el poder era reversible, es decir, que no siempre el grupo hegemónico poseerá ese poder, pueden revertirse las posiciones entre dominantes y dominados (Foucault, 2012:77). Entonces, ¿por qué no se ha manifestado una resistencia por parte de los periodistas y la sociedad ante un mito que norma conductas, establece relaciones de poder y al mismo tiempo lo ejerce? ¿cuánto está dispuesta la sociedad a permitir y aceptar como válido del mito? ¿cuáles son los límites que pone la sociedad ante el poder del periodismo? o ¿será que el periodismo ha perdido su valor y, por lo tanto, mantener la ilusión del mito es simplemente eso; sostener una ilusión que no tiene relación con la práctica real por lo que su poder no es realmente una amenaza? Mantener la ilusión significa mantener la idea de poder como también el sentimiento de grandeza. El relato mítico no sólo es la explicación de la profesión, sino también una capa protectora y un salvavidas para los periodistas, quienes se sujetan a él a modo de justificar y legitimar su rol en la sociedad. El mito permite que jóvenes estudiantes y viejos 
Valentina Rey Domínguez

profesionales, sueñen en grande; sientan el poder que les otorga su profesión y al mismo tiempo, el estatus moral que adquieren por ser periodistas: profesionales con un deber y sentido ético.

\section{Bibliografía}

Barthes, Roland (1966). Critique et vérité. Paris: Seuil.

Arancibia, J.P. (2005). "El lenguaje y lo político: de la Parresía Clásica al totalitarismo mediatizado." En: Comunicación y política. Fragmentos para una genealogía de la mediatización en Chile: Arcis

Barrera, C. (2004). Historia del periodismo universal. Barcelona: Ariel.

Canel, M.J y Sádaba, T. (1999): "La investigación académica sobre las actitudes profesionales de los periodistas. Una descripción del estado de la cuestión.” En: Comunicación y sociedad. Vol. XII.

Canel, M.J y Sánchez - Aranda, J.J (1999). La influencia de las actitudes profesionales del periodista español en las noticias. Universidad de Navarra. Departamento de educación pública.

Chillón Lorenzo, J. M. (2009). "Crítica y objetividad contra dogmatismo: lecciones popperianas para el periodismo informativo”. En: Estudios sobre el mensaje periodístico, vol. 15. pp. 157-173

Código de Ética (2015). Santiago de Chile: Colegio de Periodistas de Chile.

Díaz, J. J. F. (1996). "Los sentidos del mito. Análisis comparativo de las visiones de R. Barthes, C. Levi-Strauss y K. Burridge”. Revista Murciana de Antropología. 3 (9-20)

Federación de Asociaciones de Periodistas de España. (1993). “Código Deontológico.”

Foro de Periodismo Argentino (2006). "Código de Ética FOPEA."

Foucault, M. (1977). Historia de la sexualidad I. La voluntad del saber. Madrid: Siglo Veintiuno

Foucault, M. (1996). La verdad y las formas jurídicas. Barcelona: Gedisa

Foucault, M. (2012). El poder, una bestia magnífica. Buenos Aires: Siglo Veintiuno

Kapuscinski, R. (2000). Los cínicos no sirven para este oficio. Barcelona: Anagrama. 
Valentina Rey Domínguez

Laclau, E. (2002). Misticismo, retórica y política. Buenos Aires: FCE

Lévi-Strauss, C. (1995). "La estructura de los mitos”. En: Antropología estructural. Trad. E. Verón. Barcelona: Paidós.

Marx, K; Engels, F. (1974). La ideología alemana. México: Ediciones de Cultura Popular

Mellado, C. (2009). "Periodismo en Latinoamérica: revisión histórica y propuesta de un modelo de análisis." En: Comunicar, no 33, v. XVII, 2009. Revista Científica de Educomunicación; ISSN: 1134-3478; Pp. 193-201

Nietzsche, F. (2006). La genealogía de la moral. Madrid: Alianza Editorial.

Ortega, F; Humanes, ML. (2000). Algo más que periodistas. Sociología de una profesión. Barcelona: Ariel.

Restrepo, J.D. (2004). El zumbido y el moscardón. Colección Nuevo periodismo: Libros del taller.

Parra Pujante, A. (2012): "La lógica periodística en sentido epistemológico.” En: Estudios sobre el mensaje periodístico, 18 (2), pp. 891-906.

Said, E. (1998): “Antagonistas, seguidores, públicos y comunidad”. En: Foster, H. Ed: La posmodernidad. Barcelona: Kairós.

Salinas, C; Stange, H. (2014). "La cultura profesional del periodista como mito". En: I Congreso de la Asociación Chilena de Investigadores en Comunicación. pp 320 -327. Santiago de Chile:

INCOM.

San Martín, R. (2008). “Contra la objetividad. El mito de la neutralidad periodística y las alternativas para repensarlo". En: Perspectivas de la comunicación. pp. 73 -80.

Tuchman, G. (1983). La producción de la noticia. Estudio sobre la construcción de la realidad. Barcelona: Gustavo Gili.

Tuchman, G. (1999). "La objetividad como ritual estratégico: un análisis de las nociones de objetividad de los periodistas”. En: Cuadernos de Información y Comunicación, nº 4. pp. 199218

Vico, E. (2013). "Las teorías profesionales y las 5 crisis del periodismo." En: CIC Cuadernos de Información y Comunicación 2013, vol. 18. 69-81. ISSN: 1135-7991

http://dx.doi.org/10.5209/rev_CIYC.2013.v18.41716

Zizek S. (2003). Ese sublime objeto: la ideología. Buenos Aires: FCE 